\title{
Investigation on the Hydration Properties of the Rice Husk Ash Cement Using Ftir and Sem
}

\author{
G. Sivakumar (Corresponding Author) \\ Centralised Instrumentation and Service Laboratory (CISL) \\ Department of Physics, Annamalai University \\ Annamalai nagar 608 002, Tamilnadu, India \\ Tel: 91-986-560-9800 E-mail: gsk_cisl@yahoo.com \\ R. Ravibaskar \\ Material Science Research Laboratory \\ Department of Physics, Annamalai University \\ Annamalainagar 608 002, Tamilnadu, India \\ Tel: 91-984-208-8302 E-mail: rrbaskarphy@ymail.com
}

\begin{abstract}
Effect of Rice husk ash on hydration properties of rice husk ash cement paste are reported in this paper. Rice Husk Ash (RHA) is used to replace $20 \%$ of Portland cement and water to solid ratio is 0.4 . The hydration products observed due to rice husk ash addition were confirmed using the characteristic peak of Fourier Transform Infrared (FTIR) spectra and the micro structural changes were noted using Scanning Electron Microscope (SEM) micrographs. The rice husk ash cement paste gains more strength due to the production of more Calcium Silicate Hydrate (CSH) gel (pozzolanic reaction products).
\end{abstract}

Keywords: Rice Husk Ash, Cement, FTIR, SEM

\section{Introduction}

Rice husk ash cement is formed by the combination of Ordinary Portland Cement (OPC) with rice husk ash (RHA). Rice husk ash (RHA) is an end product of the combustion of rice husk (or hull). Unlike other pozzolanic materials, the concrete incorporating the RHA shows excellent strength development at early-age even without steam-cure (Wada I. et al., 2000). Burned rice husk give $14-20 \%$ ash by weight which contains approximately $90 \%$ by weight silica and minor amounts of other elements.

Many researchers, have investigated the possible addition of rice husk ash (10\% to $30 \%)$ as a supplementary cementitious material. RHA is a mineral admixture for concrete and a lot of mechanical data (Ganesan et al., 2008; Gemma Rodriguez de Sensale, 2006; Saraswathy and Ha-Won Song, 2006) has been published. The literature regarding the effect of the RHA on molecular vibration and micro structural is vague. Therefore, the main objective of this study is to evaluate and compare the effect of rice husk ash in rice husk ash cement paste with the OPC using FTIR and SEM.

\section{Materials and Methods}

The materials used in this investigation consist of market available Ordinary Portland Cement (ASTM type I) and Rice Husk Ash (RHA) collected from Modern Rice Mill, Erukur, Tamil Nadu, India. The chemical composition of OPC and RHA are given in Table. 1. It reveals the highly siliceous $\left(\mathrm{SiO}_{2}-92.78 \%\right)$ nature of the ash. The partial replacement of cement by rice husk ash in weight percentage is carried out for OPC $+0 \% \mathrm{RHA}$ and $\mathrm{OPC}+20 \% \mathrm{RHA}$. The samples were hydrated with distilled water at the water to solid ratio (w/s) is 0.4 and different hydration intervals. 
Setting time of the OPC and rice husk ash cement samples were measured by the penetration resistance method in accordance with the ASTM C 403 using the standard procedure and strength measurement was conducted for the samples using ASTM C 349 method and its results are given in Fig. 1(a) and (b).

The Infrared spectra are recorded using Perkin Elmer model RX-1 FTIR spectrometer for the powdered samples are made to a pellet by mixing with KBr. For SEM study, a thin layer of fractured surface of sample is mounted on the stub using double sided adhesive carbon tape. The specimens are coated with the help of gold coater (JEOL auto fine coater model JFS-1600, coating time is 120 seconds with $20 \mathrm{~mA}$ ). The micrographs are recorded using JEOL SEM model JSM-5610 LV available at CISL, Annamalai University, Tamil Nadu, India.

\section{Results and discussion}

\subsection{FTIR study}

FTIR spectra of the hydrated OPC and OPC $+20 \%$ RHA samples are shown in Fig. 2 and 3. In the 1hour OPC spectrum (Fig. 2a), the $\mathrm{OH}$ stretching band at $3640 \mathrm{~cm}^{-1}$, symmetric stretching $\left(v_{1}\right) \mathrm{H}_{2} \mathrm{O}$ at $3415 \mathrm{~cm}^{-1}$, asymmetric stretching vibrations $\left(v_{3}\right)$ carbonate at $1460-1420 \mathrm{~cm}^{-1}, v_{3}$-sulphate doublet at1090 and $1150 \mathrm{~cm}^{-1}$ and $v_{3}$-silicate at $917 \mathrm{~cm}^{-1}$ and out-plane $\left(v_{4}\right)$ carbonate at $874 \mathrm{~cm}^{-1}, v_{4}$-sulphate at $660 \mathrm{~cm}^{-1}$ and $v_{4}$-silicate at $519 \mathrm{~cm}^{-1}$ and in-plane bending vibrations $\left(v_{2}\right)$ $\mathrm{H}_{2} \mathrm{O}$ at $1610 \mathrm{~cm}^{-1}, v_{2}$-sulphate at $610 \mathrm{~cm}^{-1}$ and $v_{2}$-silicate at $462 \mathrm{~cm}^{-1}$ bending vibrations are present (Harchand et al., 1980; Mollah et al., 1999; Hassaan M Y \& Abdel N. Hakeem, 1989; Mollah et al., 2000; Ghosh S N \& Chatterjee A K, 1974; Hanna et al., 1995). The $v_{3}$ sulphate doublet bands transform to a singlet $\left(1102 \mathrm{~cm}^{-1}\right)$ on 1 day hydration (Taylor H F W, 1990). It is indicative of early faster dissolution of gypsum and other alkali sulphates, and ettringite formation. Water stretching band at $3415 \mathrm{~cm}^{-1}$ has grown in intensity with a shift $\left(3438 \mathrm{~cm}^{-1}\right)$ compared to 1 hour, while the intensity of $v_{4}$ and $v_{2}$ sulphates have reduced. The shift of water stretching band may be due to conversion of ettringite to monosulphate (Sivakumar et al., 2009)

$$
\begin{array}{rr}
\mathrm{C}_{3} \mathrm{~A}+\underset{(\text { Gypsum })}{3 \mathrm{C} \overline{\mathrm{S}} \mathrm{H}_{2}+26 \mathrm{H}} \rightarrow & \multicolumn{1}{c}{\mathrm{C}_{6}{\mathrm{~A} \overline{\mathrm{S}_{3}} \mathrm{H}_{32}} \rightarrow} \\
& \text { (Ettringite) } \\
2 \mathrm{C}_{3} \mathrm{~A}+\mathrm{C}_{6} \mathrm{~A}_{3} \mathrm{H}_{32}+4 \mathrm{H} \rightarrow & 3 \mathrm{C}_{4} \mathrm{~A} \overline{\mathrm{S}} \mathrm{H}_{12} \\
& \text { (Monosulfate) }
\end{array}
$$

The shifting of $v_{3}$ silicate towards higher frequency $\left(917 \mathrm{~cm}^{-1}\right.$ to $\left.980 \mathrm{~cm}^{-1}\right)$ with an intensity variation may be attributed to precipitation of colloidal suspension of amorphous CSH (Flores-Velez L M A \& Dominguez O, 2002), as a result of reaction of $\mathrm{C}_{3} \mathrm{~S}$ and $\mathrm{C}_{2} \mathrm{~S}$ with water according to the following reactions,

$$
2 \mathrm{C}_{3} \mathrm{~S}+6 \mathrm{H} \rightarrow \mathrm{C}_{3} \mathrm{~S}_{2} \mathrm{H}_{3}+3 \mathrm{CH}
$$

$$
2 \mathrm{C}_{2} \mathrm{~S}+4 \mathrm{H} \rightarrow \mathrm{C}_{3} \mathrm{~S}_{2} \mathrm{H}_{3}+\mathrm{CH}
$$

Cement chemistry notation: $\mathrm{C}=\mathrm{CaO} ; \mathrm{S}=\mathrm{SiO}_{2} ; \mathrm{A}=\mathrm{Al}_{2} \mathrm{O}_{3} ; \mathrm{F}=\mathrm{Fe}_{2} \mathrm{O}_{3} ; \mathrm{S}=\mathrm{SO}_{3} ; \mathrm{H}=\mathrm{H}_{2} \mathrm{O}$

The $v_{3}$-silicate shifting through 63 wave numbers indicate the beginning of setting and strength development. This result is well manifested through Fig. 1. The formation of $\mathrm{Ca}(\mathrm{OH})_{2}$ is a by product of $\mathrm{C}_{3} \mathrm{~S}_{\text {and }} \mathrm{C}_{2} \mathrm{~S}$ reaction and has contributed a strong and sharp peak (1day onwards) at $3640 \mathrm{~cm}^{-1}$. The $v_{2}-\mathrm{OH}$ band at $1610 \mathrm{~cm}^{-1}$ has not only grown but also moved to higher frequency $\left(1630 \mathrm{~cm}^{-1}\right)$. This can be attributed to greater restriction of vibration due to incorporation of water molecules into the cement matrix.

The $v_{3}$ silicate band ( $4^{\text {th }}$ week spectra) at $519 \mathrm{~cm}^{-1}$ decreases while $v_{2}$ silicate at $462 \mathrm{~cm}^{-1}$ has an increase in intensity. This is a finger print evidence for the higher degree of silicate polymerization of the precipitated CSH. It indicates the completion of hydration in this stage and well coincide with the compressive strength results.

Hydrated RHA cement (OPC+20\% RHA) sample (Fig.3) have the same mode of vibration of oxides as that of control. However they observe some differences, the characteristic RHA band at $1095 \mathrm{~cm}^{-1}$ gets a stronger intensity at 1 hour spectrum. From 1 day a decreasing trend in intensity is observed. It indicates the starting of pozzolanic reaction. The RHA peak at $1095 \mathrm{~cm}^{-1}$ fades with time but consistently consumed to yield CSH hydrate according to the following reaction (pozzolanic reaction),

$$
2 \mathrm{SiO}_{2}+3 \mathrm{Ca}(\mathrm{OH})_{2} \rightarrow 3 \mathrm{CaO} \cdot 2 \mathrm{SiO}_{2} \cdot 3 \mathrm{H}_{2} \mathrm{O}
$$

From 1 day, the relative intensity changes between $v_{4}$ and $v_{2}$ silicate bands are also faster in rice husk ash cement. The $v_{3}$ silicate band $(\mathrm{CSH})$ has higher energy with strong intensity in rice husk ash cement. The pozzolanic reaction is higher in rice husk ash cement at 28 days which accelerates the rate of reaction and enhances the strength. 


\subsection{SEM Study}

Hydrated SEM micrographs of OPC and rice husk ash cement sample are shown in Fig. 4 \& 5 respectively. From 1hour OPC micrograph (Fig.4a), the anhydrous cement particles appear much brighter than hydrated products. The initial hydration has produced textural changes on the surface due to formation of a discontinuous layer of some hydration product. At 1 day (Fig.4b) micrograph, the hydration products of ettringite (E) needles are seen on the cement grains. After 1 day the initial frame work of ettringite needles start to disappear and it is replaced by tightly packed oriented long rods indicating $\mathrm{CH}$ crystals.

From the 1week micrograph (Fig.4c), the ettringite needles are not shown. The hexagonal shaped $\mathrm{CH}$ crystals $\left(\mathrm{Ca}(\mathrm{OH})_{2}\right)$ with large crystalline particles and the foil honey-comb structure of calcium silicate hydrate (CSH) are present in the micrograph. It is indicate that the hydration reaction. Since the CSH and $\mathrm{CH}$ comprised over $75 \%$ of the hydrated cement paste, it plays a major role in determining the strength of the cement. As time passes (after 1week onwards), a better crystallization of the CSH formation is observed in the $4^{\text {th }}$ weeks (Fig. 4d) micrograph. This massive structure (Mohanraj et al., 2007) has more rigidity. It is evidence for a higher degree of silicate polymerization of the precipitated CSH in the later periods. These observations well coincide with the compressive strength results.

The hydration product of the rice husk ash cement sample is similar to the OPC sample. The surface of the RHA particles are covered by hydration products and more unreacted RHA are seen with cement grains in 1 hour micrographs Fig. 5a. From 1 day (Fig.5b) microstructure of Rice Husk Ash cement, AFm phases, CH and CSH products are observed. Probably a shift from AFt to AFm phases might have been occurred. The ettringite needles disappear and the CH crystals diminish due to the pozzolanic reaction. In 1week micrograph (Fig.5c) the pores are being filled with CSH and by product of AFm phases, thereby AFm phases occupy more space. As time passes the rate of hydration reaction is faster than OPC and thus producing more secondary $\mathrm{CSH}$.

Micrographs of matured age $\left(4^{\text {th }}\right.$ week $)$ have more compact dense microstructure than OPC. The volumes of $\mathrm{Ca}(\mathrm{OH})_{2}$ crystal are reduced and higher volume of CSH than OPC are seen and consequently accelerates and enhances the hydration (Papadakis, V.G. and E.J. Perdersen., 1999).

\section{Conclusion}

From the above results, the indication of pozzolanic reaction is evolving and that part of the amorphous silica in the ash is released into the matrix, combining available $\mathrm{CH}$ and forming a second generation $\mathrm{CSH}$ improving the strength of the system. The pozzolanic activity of rice husk ash produces more amount of CSH in the rice husk ash cement sample. Hence rice husk ash acts as a good pozzolanic material and can be blended with cement.

\section{References}

Flores-Velez L M A \& Dominguez O. (2002). J Mater Sci, 37, 983-988.

Ganesan, K., K. Rajagopal and K. Thangavel. (2008). Con. Build. Mat., 22: 1675-1683.

Gemma Rodriguez de Sensale. (2006). Cem. Concr. Compos., 28: 158-160.

Ghosh S N \& Chatterjee A K. (1974). J Mater Sci, 10, 1574-1584.

Hanna R A, Barrie P J, Cheeseman C R, Hills C D, Buchler D.M \& Perry R. (1995). Cem Concr Res, 25(7), 1435-1444.

Harchand K S, Vishwamittar \& Chandra K. (1980). Cem. Concr. Res, 20, 243 -252.

Hassaan M Y \& Abdel N. Hakeem. (1989). J Mater Sci Lett, 8, 578-580.

Mohanraj. K., R. Ravibaskar, B. Shanthi and G. Sivakumar. (2007). Eco-Chronicle, 2, 91-96.

Mollah M Y A, Thomas R. Hess, Yung-Nian Tsai \& Cocke D L. (1999). Cem Concr Res, 23, 773-784.

Mollah M Y A, Wenhong Yu, Robert Schennach \& David L. Cocke. (2000). Cem Concr Res, 30, 267-273.

Papadakis, V.G. and E.J. Perdersen. (1999). Cem. Concr. Res., 30: 291.

Saraswathy, V and Ha-Won Song. (2006). Con. Build. Mat.

Sivakumar, G., K. Mohanraj and S. Barathan. (2009). E. Journal of Chemistry, 6(1), 231-236.

Taylor H F W. (1990). Cement Chemistry. Academic Press, Inc., New York.

Wada I., T. Kawano, M. Kawakami and N. Maeda. (2000). Proceedings of the Fifth CANMET/ACI International conference on Durability of Concrete, vol. I, SP-192, Barcelona Spain, pp. 205-222. 
Table 1. Results of chemical analysis of OPC and RHA

\begin{tabular}{|c|c|c|c|c|c|c|c|c|c|c|}
\hline \multirow{2}{*}{ Composition } & $\mathbf{C a O}$ & $\mathrm{SiO}_{2}$ & $\mathrm{Al}_{2} \mathbf{O}_{3}$ & $\mathbf{F e}_{2} \mathbf{O}_{3}$ & $\mathbf{S O}_{3}$ & $\mathbf{M g O}$ & $\mathbf{N a}_{2} \mathbf{O}$ & $\mathbf{K}_{2} \mathbf{O}$ & LOI & others \\
\hline OPC & 63.0 & 21.79 & 5.75 & 3.25 & 2.35 & 1.97 & 0.50 & 0.28 & 1.0 & 0.11 \\
\hline RHA & 1.05 & 92.78 & 0.20 & 0.38 & 0.35 & 0.45 & 0.58 & 1.26 & 1.98 & 0.97 \\
\hline
\end{tabular}

(a)

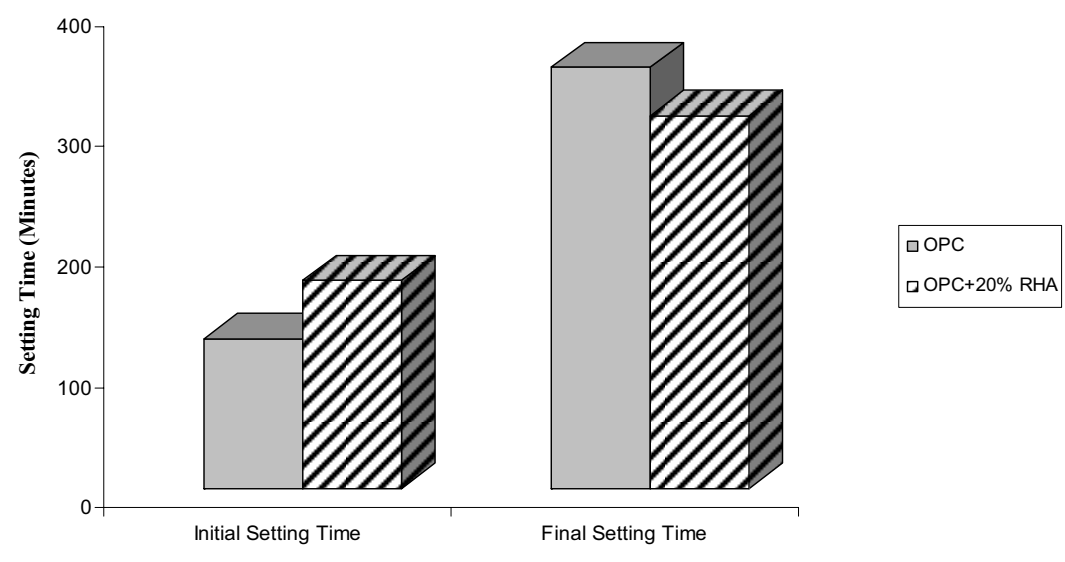

Figure 1. (a) Setting time of the samples

(b)

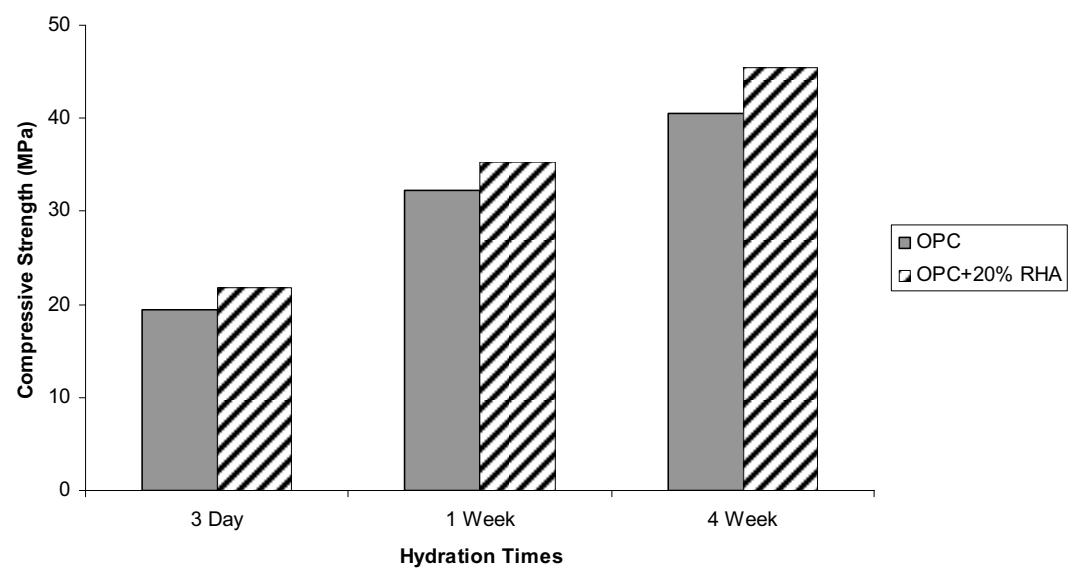

Figure 1. (b) Compressive strength of the samples 


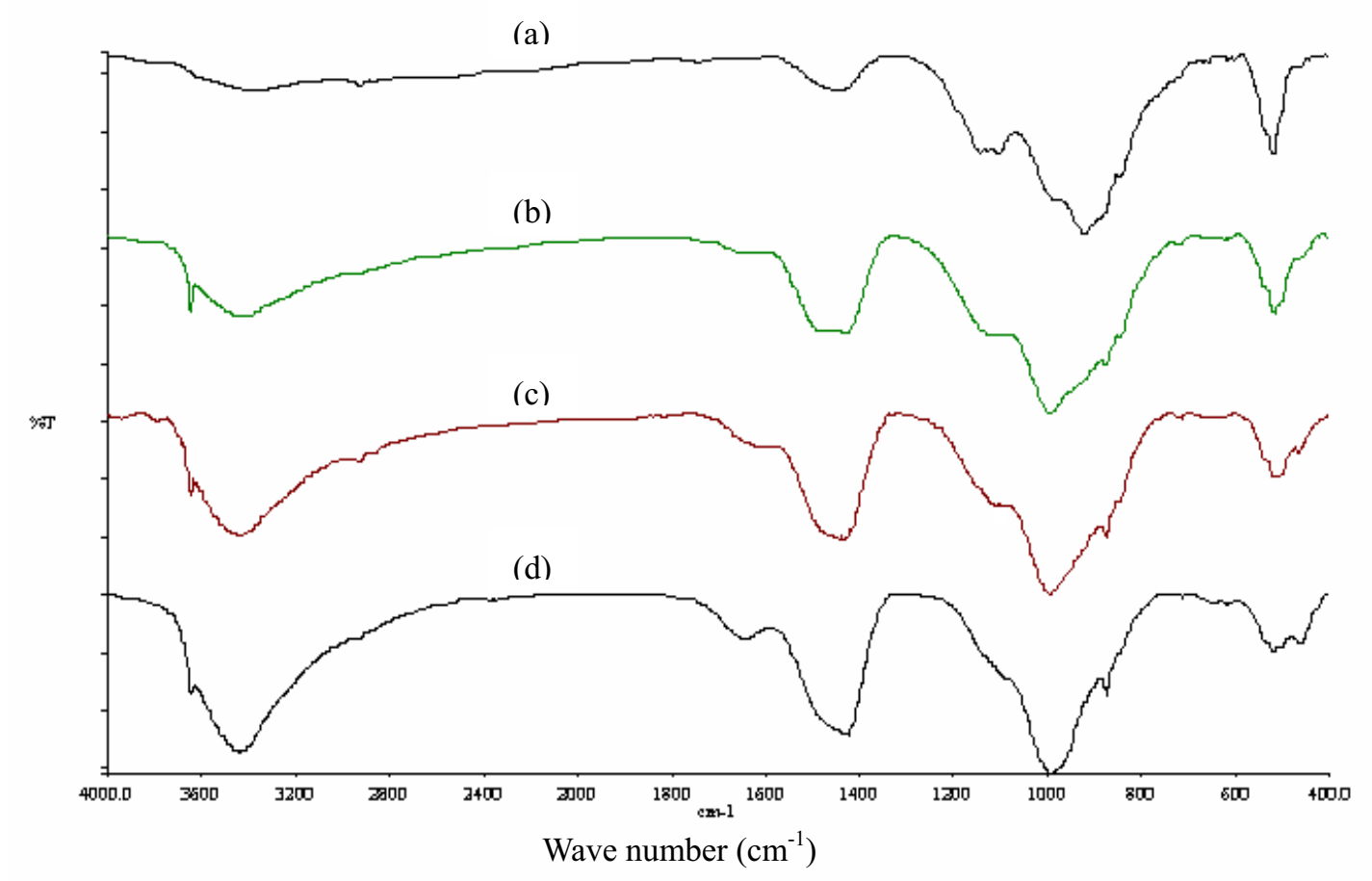

Figure 2. FTIR spectra of OPC sample hydrated for (a) 1hour, (b) 1day, (c) 1week and (d) 4weeks

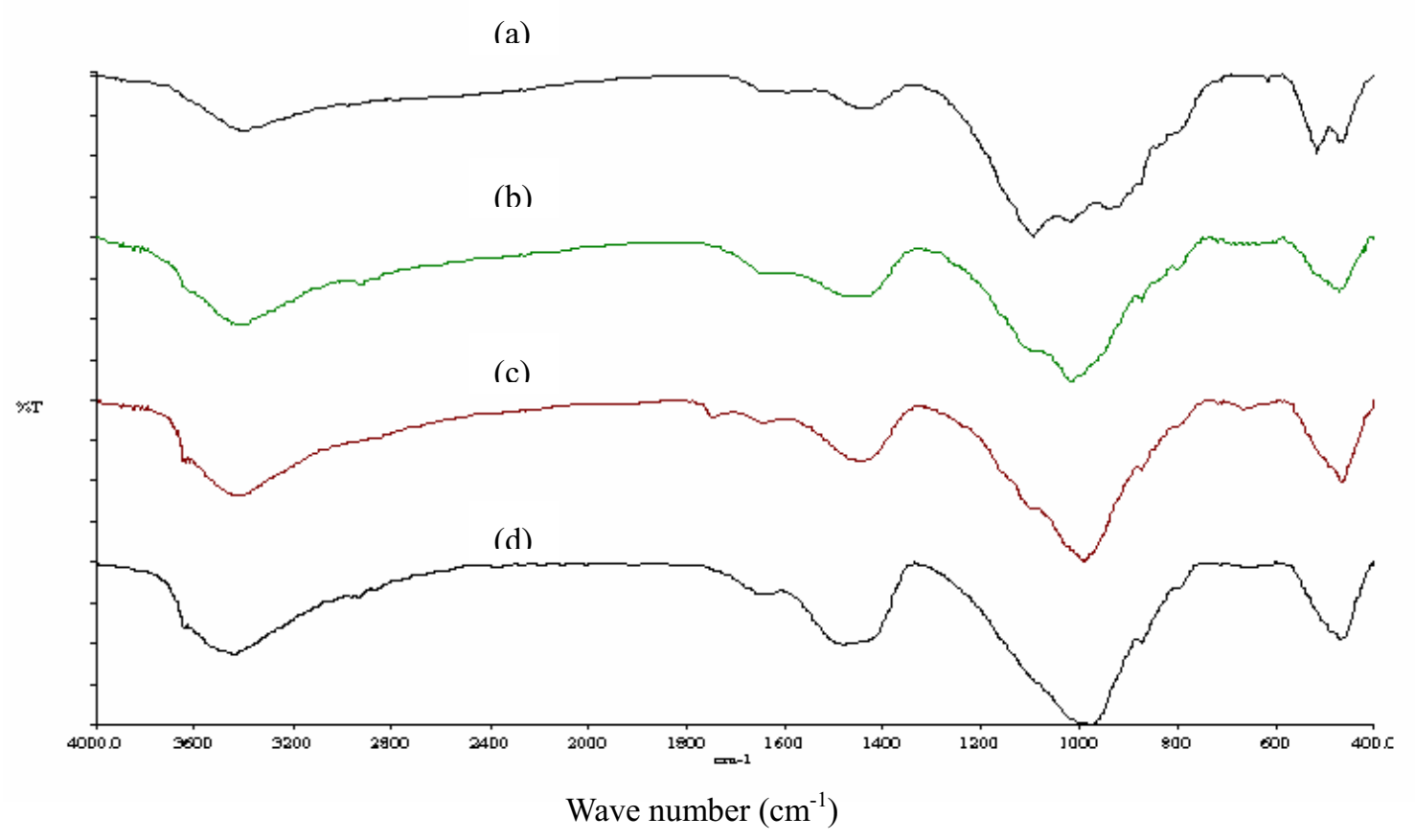

Figure 3. FTIR spectra of OPC $+20 \%$ RHA at (a) 1hour, (b) 1day, (c) 1week and (d) 4weeks 

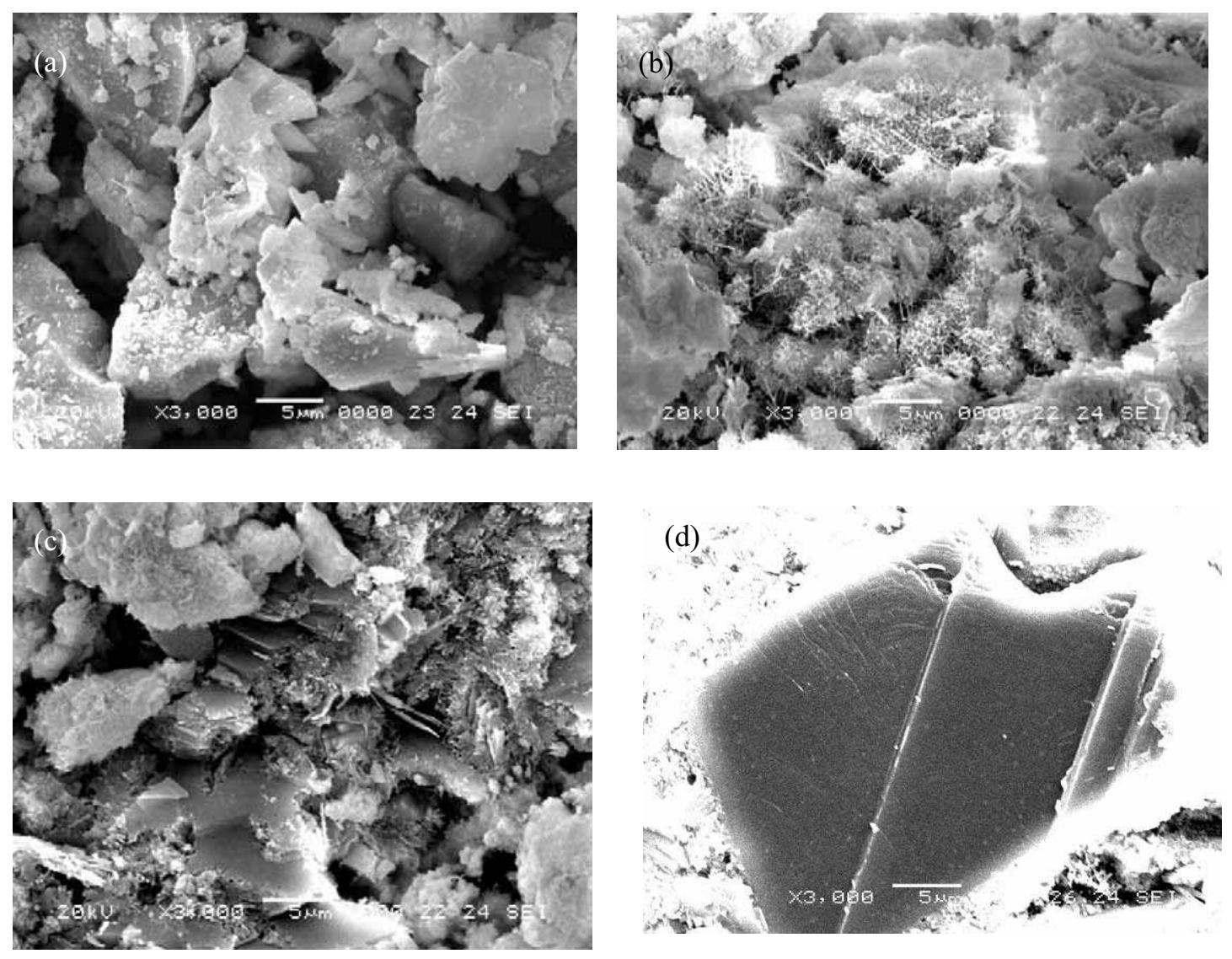

Figure 4. SEM micrographs of OPC at (a) 1hour, (b) 1day, (c) 1week and (d) 4weeks 

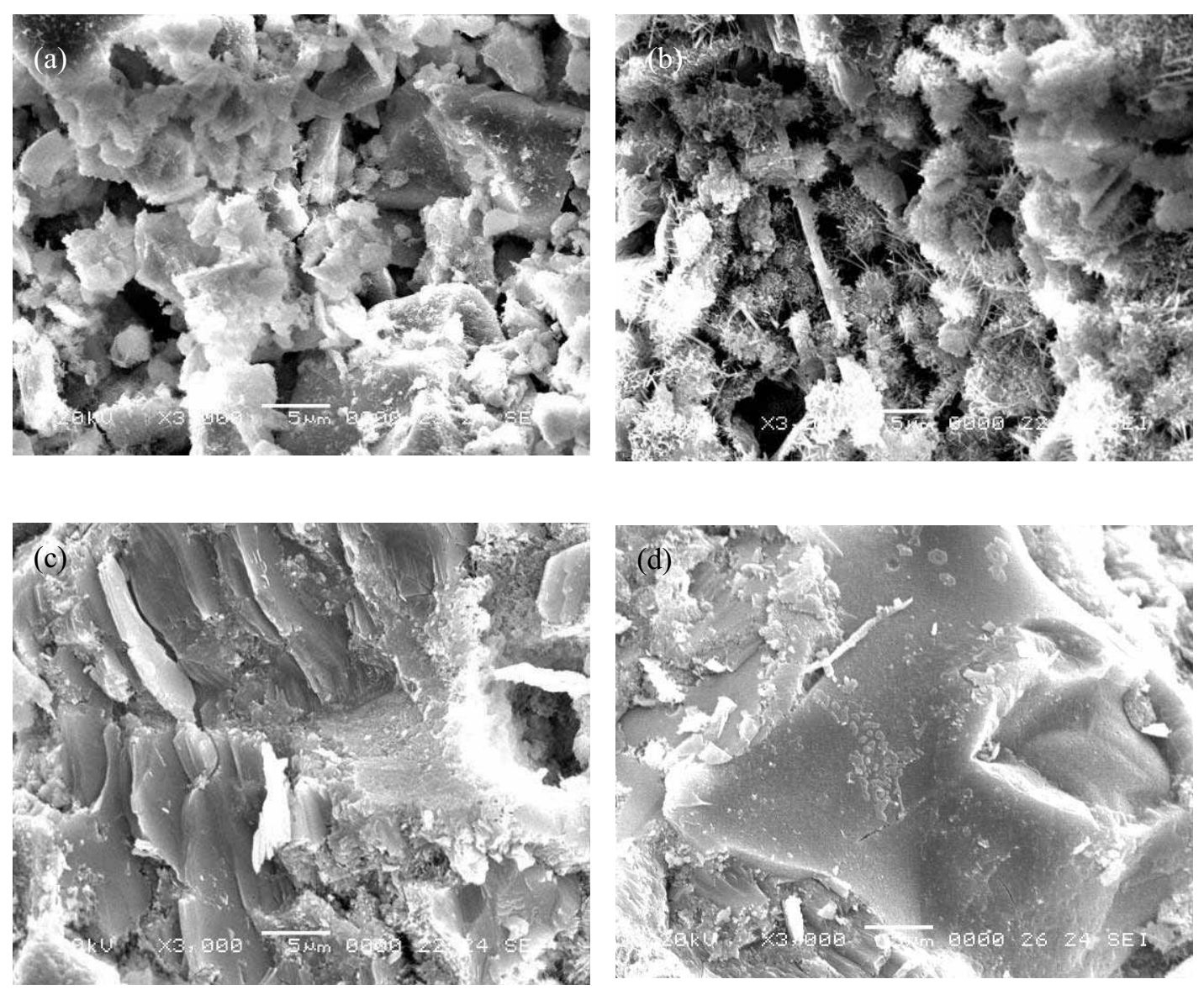

Figure 5. SEM micrographs of hydrated Blended samples at (a) 1hour, (b) 1day, (c) 1week and (d) 4weeks 